\title{
ИСТОРИЯ СЕМЬИ
}

\author{
А.А. Мойса

\section{КАТАРИНА ФОН БОРА: ОСОБЕННОСТИ ПРОТЕСТАНТСКОГО БРАКА B НАЧAМE XVI BEKA}

КАючевЫЕ словА: брак, Реформация, Катарина фон Бора, Мартин Аютер, протестантизм

АннотАция: В статье автор рассматривает особенности протестантского брака, основы которого были заложены реформаторским Авижением в начале XVI века. В исследуемый период в мютеранском учении брачный союз приобретает особое значение, обусловленное критикой католического идеала целибата и аскезы. Новый тип супружества автор статьи стремится раскрыть сквозь призму биографии Катарины Аютер (в Аевичестве фон Бора), яркой представительницы своей эпохи. При этом, поАнимается вопрос, как супружеские нормы, зафиксированные в трудах Мартина ^ютера, воплотились в его собственной семье. Исследование строится на обширной источниковой базе: свидетельствах современников, собранных в "Застольных беседах", Аанных мичной переписки ^ютера со своими сподвижниками и корреспонденции его супруги. Опираясь на собранный источниковый материал, освещающий жизнь Катарины, автор раскрывает роль женщины, как жены и матери, и выявляет её возможности и права в формируемом протестантском обществе. Таким образом, Ааётся оценка тому, как союз главы Реформации и его жены, ставший нагляАным примером супружеских отношений, повлиял на Аальнейшее совершенствование семейного института.

Перечисляя отличительные черты протестантизма, расцветшего в немецких землях в годы Реформации, нельзя не упомянуть такие составляющие, как переосмысление брака и возвышение позиций семьи. Идеал целомудрия, господствовавший в католическом учении, был подвергнут сомнению. В своих трудах Мартин Лютер постоянно упоминал

Анна Александровна Мойса, бакалавр Российского государственного гуманитарного университета, mojsa.an@yandex.ru

DOI: 10.32608/2307-8383-2020-28-6-23 


\section{Мойса А.А. Катарина фон Бора}

слова божьи, обращённые к Адаму и Еве: «плодитесь и размножайтесь»1. Таким образом, он критиковал целибат и доказывал, что брачная жизнь и рождение детей являются важной задачей человечества, утверждённой самим Богом.

Тем не менее, активно призывая своих сторонников вступать в брак, сам Лютер не спешил жениться. Одной из наиболее вероятных причин подобных колебаний стало то, что богослов опасался повредить своей репутации: он должен был оставаться для других Пророком, идеалом благочестия. Разрешая священникам жениться, Лютер настаивал на том, чтобы они не терзали себя обетами, которые не в состоянии выполнить. Таким образом, он советовал им примириться с человеческой слабостью. Однако то, что было позволено слабому, могло бросить тень на авторитет такой значимой фигуры, как предводитель Реформации.

Дилемма Лютера решилась сама собой, когда в 1523 году в Виттенберг прибыли монахини, сбежавшие из цистерцианского монастыря Нимбшен. В течение двух лет богослов ломал голову над тем, как бы сосватать беглянок за своих друзей и знакомых. Одну из них, Катарину фон Бора, никак не получалось пристроить, девушка отличалась тяжёлым характером и наотрез отказывалась выходить замуж за тех, кто был ей не мил. По свидетельству Амсдорфа бывшая монахиня сама поставила условие: она пойдёт под венец лишь с самим главой Реформации 2 .

Её желанию суждено было сбыться: свадьба состоялась в июне 1525 года. Интересно, что Лютер в том же месяце в своём послании к Амсдорфу приводил сразу несколько оправданий для своего решения: во-первых, он надеялся, что

1 Бт. 1:28.

2 Гобри. 2000: 272. 
ему не так уж много осталось жить на земле; во-вторых, он исполнил волю отца, который давно настаивал на женитьбе своего единственного сына; в-третьих, ссылался на то, что наконец решился вдохновить других своим личным примером. Лишь одна довольно прохладная строчка в письме посвящена непосредственно новобрачной: «Я и не влюблен, и не пылаю страстью, но всё же люблю свою жену» ${ }^{3}$. Создаётся ощущение, что Лютер едва ли рад своему новому статусу, скорее, он смиряется с ним, говоря, что такой исход был угоден Богу. Итак, теперь самому реформатору предстояло пройти испытание супружеской любовью, которую он так часто воспевал в своих трудах.

Отличалась ли семейная жизнь четы Лютеров от формулы, которую богослов вывел, ещё будучи холостяком в «Проповеди о супружеском положении» (1520 г.) и в сочинении «0 супружеской жизни» (1522 г.)? Смогла ли Катарина фон Бора повлиять на взгляды своего мужа? Проанализировав свидетельства современников и личную переписку, мы постараемся пролить свет на характер спутницы Лютера и оценить её поступки, сравнив их с идеалами реформационного брака.

Несмотря на то, что исследование творчества сподвижников Лютера ведётся до сих пор, на данный момент Веймарское собрание (D. Martin Luthers Werke. Weimar, 19121921) является наиболее полной публикацией источников, дающих представление о знаменитых «Застольных речах» («Tischreden») богослова. При изучении этого источника необходимо помнить, что Лютер едва ли планировал свою речь заранее, говорил довольно резко и категорично. Хотя в дальнейшем записи и редактировались для публикации, за- 


\section{Мойса А.А. Катарина фон Бора}

метно, что у себя дома он снимал маску избранного пророка и показывал свою человеческую сторону, аргументируя свои утверждения не только библейскими цитатами, но и примерами из повседневной жизни. Образ Лютера почти всегда затмевает собой других участников застолья, тем не менее, в большинстве случаев «речи» придерживаются формата дискуссии, исходя из которой мы можем почерпнуть некоторые сведения об окружении реформатора, о людях, которые были не прочь задать ему вопросы или даже вступить с ним в спор.

К последним относилась и постоянная участница застолий, хозяйка дома, Катарина фон Бора. Веймарское издание насчитывает более 160 прямых и косвенных упоминаний жены Лютера4: при этом она фигурирует в них и в качестве яркого примера, приводимого её мужем, и в качестве его партнёра или оппонента в очередной полемике.

Что же говорил Лютер о своей супруге? С одной стороны, он был верен своим проповедям, множество раз подчёркивая, что жену необходимо ценить, о хорошей спутнице жизни стоит тщательно молить Бога, как он и сделал перед своим браком5. Реформатор утверждал, что его Ката дороже ему, чем Франция и Венеция вместе взятые. Ведь она являлась созданием, подаренным ему Богом, была верной женой и хорошей матерью, принёсшей ему много детей. С другой стороны, в это описание, полностью соответствовавшее лютеровским канонам, вкрадывались нотки обыденной жизни: так Лютер сознавался, что от Катарины он слышал куда меньше глупостей, чем от чужих жён ${ }^{6}$.

4 Kramer. 2016: 165.

5 TR 1, 84, 6-9, Nr. 185.

6 TR 2, 281, 29-35, Nr. 1965. 
Гордость Лютера за жену активно проявлялась в его борьбе против монашеских обетов и целибата. Рассматривая портрет Катарины, выполненный Лукасом Кранахом, реформатор попросил художника нарисовать и его, чтобы изображения мужа и жены составляли пару, и их можно было бы прислать на предстоящий Мантуанский собор (1537 г.). Пускай тогда святые отцы, глядя на их портреты, скажут, что лучше: супружество или целибат ${ }^{7}$.

Гордясь супругой, Лютер не забывал похвалить и себя, заявляя: «Ката, у тебя благочестивый муж, который тебя любит, ты императрица. Помни это и благодари Бога» ${ }^{8}$. Тем не менее, он также не скрывал, что Катарина значит для него не меньше, чем его учение. Нежное отношение к жене часто проявляется в теологических размышлениях Лютера, он охотно проводит параллели, упоминая её имя. «Бог должен быть ко мне куда дружелюбнее и говорить со мной, как моя Ката с её Мартинхеном» ${ }^{9}$, - автор подчёркивает материнскую заботу детях, одну из основ гармонии протестантского брака. Имя Катарины стоит в одном ряду с Меланхтоном, Лютер заявляет, что полагается на них больше, чем на Христа ${ }^{10}$. 0 большом доверии к жене свидетельствует и другая цитата: «Послание к Галатам - моя epistelcha, которой я доверил себя. Это моя Ката фон Бора»11.

В то же время Лютер охотно говорил о недостатках своей Каты, противопоставляя её идеалу женской покорности. Так он упоминал, что до свадьбы она не нравилась ему, он

7 TR 3, 378, 9-11, Nr. 3528.

8 TR 1, 554, 25, Nr. 1110.

9 TR 2, 4, 29-32, Nr. 1237.

10 TR 2, 66, 12-13, Nr. 1352.

11 TR 1, 69, 18-19, Nr. 146. 


\section{Мойса А.А. Катарина фон Бора}

считал её гордячкой ${ }^{12}$. Перечисляя людей и обстоятельства, при столкновении с которыми необходимо проявлять терпение, Лютер начинает свой список с дьявола и дворян, а заканчивает собственной женой 13 . Главное качество, которое он определял для женщины - послушание, тоже не всегда было свойственно его супруге. Лютер косвенно упрекает её, заявляя, что если бы ему пришлось ещё раз жениться, то ему бы хотелось послушную жену из камня, так как он отчаялся найти послушание в женщине ${ }^{14}$.

Не менее значимым источником для исследования личности Катарины фон Бора становится переписка. Речь идёт не только о её личной корреспонденции, но и об упоминаниях жены Лютера в реформаторских кругах: на данный момент обнаружено около 500 писем, в которых современники так или иначе ссылаются на Катарину. Конечно, значительная часть упоминаний принадлежит самому Лютеру: его жена фигурирует в 330 письмах. Ни один корреспондент XVI века не упоминал свою супругу так часто, как это делал Лютер 15 .

Благодаря письмам мы можем проследить, как со временем трансформировалось отношение Лютера к жене. Они состояли в активной переписке, но, к сожалению, послания Катарины к мужу были полностью утрачены. Связано это с тем, что Лютер не очень заботился о том, чтобы собирать письма супруги, а его окружение не сочло их достаточно важными, чтобы сохранить ${ }^{16}$. Таким образом, на настоящий момент выявлено лишь 21 письмо из супружеской переписки, охватившей временной промежуток с 1529 по 1546 год.

12 TR 4, 504, 20-21, Nr. 4786.

13 TR 2, 347, Nr. 2173.

14 TR 2, 300, Nr. 2034.

15 Kramer. 2016: 43.

16 Kramer. 2016: 58. 
Тем не менее, примерное представление о том, что писала Катарина мужу, мы можем сформировать из его собственных ответов.

Стоит начать с того, что обращения Лютера к жене довольно разнообразны: в каждом письме он называет её поновому. Зачастую богослов высмеивает официальный характер приветствий, прибавляя к имени супруги разные титулы. Иногда он обращается к ней в мужском роде, величая её своим «доктором», «господином». В шутку он называет её «господином Кате», играя с каламбуром: её имя созвучно слову «цепь» ${ }^{17}$. Косвенно это вновь подтверждает мнение, что характер Катарины не отличался покорностью и она любила быть на равных с мужем.

Тем не менее, приветствия Лютера всегда отдают должное и добродетелям жены: богослов уважал Катарину, мог положиться на неё во многих делах и ценил её ум. Так наравне с нежными эпитетами («дорогая», «святейшая», «милостивая», «сердечно любимая») встречаются, например, такие слова, как «глубоко образованная женщина»18.

Ранние письма Лютера (1529-1530 гг.) примечательны тем, что в них он доверяет жене функцию своего посредника. Например, он сообщает Катарине о результатах встречи с Цвингли, Эколампадием и Буцером в Марбурге и просит её пересказать самые важные моменты теологической дискуссии духовным лицам Виттенберга ${ }^{19}$. При этом она должна была использовать латинские термины, ещё одно свидетельство того, что даже после бегства из монастыря Нимбшен её знания латыни не были забыты. Лютер сам следил за

17 die Kette (нем.) - цепь.

18 Luther. 1546a.

19 Luther. 1529. 


\section{Мойса А.А. Катарина фон Бора}

тем, чтобы его жена, ведя хозяйство и воспитывая детей, обращалась к книгам, напоминая о том, что ей нужно читать Евангелие 20.

Реформатор часто передавал через жену последние новости, например, в одном письме он просит сообщить всем в Виттенберге, что вскоре сядет за новое сочинение. Её же призывал контролировать публикации его трудов, к примеру, «Проповедь о том, что нужно посылать детей в школу» он просил забрать у одного издателя и передать другому ${ }^{21}$. Также он информировал её о развитии церковнополитических событий, спрашивал её совета в выборе кандидата для проповеди: «Ты, как умная женщина, могла бы помочь и посоветовать» 22.

Хлопоты по хозяйству затрагиваются почти во всех письмах, стараниями Катарины семья Лютеров обеспечила себя постоянным пропитанием: бывшая дворянка трудились в поле, разводила свиней, карпов и получала приличную выручку за пивоварение. Лютер высоко ценил её последний навык и даже в отъезде писал:

Ты хорошо поступаешь, когАа посылаешь мне сюда весь погреб моих вин и бочку твоего пива так часто, как можешь ${ }^{23}$.

Он полностью доверял ей в ведении хозяйственных дел, разрешая продавать и заказывать всё, что она может ${ }^{24}$. Такое разграничение обязанностей богослов аргументировал довольно просто: он так сильно занят своей работой, что Бог позаботился о нём и дал такую жену, при которой хозяйство

20 Luther. 1546a.

21 Luther. 1530a

22 Luther. 1530b

23 Luther. 1534

24 Luther. 1541 
будет процветать, а Лютеру не придётся брать на себя заботу о нём 25 .

К концу жизни реформатор сильно страдал от различных болезней: о своём здоровье он шутливо отчитывался в каждом письме: «Мы всё ещё бодры и здоровы и живём как князья» 26. Катарина и тут проявляла свои способности, терпеливо леча его диетой, травами, припарками и массажем. Не удивительно, что Лютер называл её медицинские познания искусством.

Мы можем легко представить, как сильно волновалась Катарина, когда здоровье мужа находилось под смертельной угрозой: в течение 1546 года Лютер почти в каждом послании просит её поменьше терзать себя и проводить время за более полезными делами, вроде чтения катехизиса:

Ты хочешь заботиться вместо Бога, будто бы он не всесилен и не может создать ещё Аесять Аокторов Мартинов 27.

В обращении к жене Лютер даже добавляет эпитет «старательная». Хоть под конец жизни богослова всё чаще поглощала меланхолия, он хотел поскорее отойти в мир иной, за неделю до смерти Лютер не без иронии благодарил её за упорство в его лечении:

Есть смысл поблагодарить тебя за твою святую заботу, когАа Аорогие святые ангелы не оберегают ${ }^{28}$.

В течение всей своей жизни Лютер не скрывал свою любовь к жене и к детям, ради которых он был готов пойти на смерть ${ }^{29}$. Тем более значимыми выглядят его размышления

25 TR 1, 73, 16-18, Nr. 154.

26 Luther. 1529

27 Luther. 1546b

28 Luther. 1546a

29 TR 2, 135, 2-4, Nr. 1563. 


\section{Мойса А.А. Катарина фон Бора}

1540 года, вследствие которых он принимает решение: когда Катарина овдовеет, именно она должна стать его единственной наследницей и опекуном их детей ${ }^{30}$. В дальнейшем эта мысль воплотится в завещании Лютера от 1542 года, реформатор настаивал, что дети должны подчиняться матери, а не она им:

Я достаточно видел и слышал, как дьявол подстрекает детей злыми и завистливыми устами, особенно когАа их матери - вАовы ${ }^{31}$.

Таким образом, забота Лютера о жене даже после смерти, доверие ей в самом важном - воспитании их детей, не оставляют сомнения в том, насколько она ему была дорога.

Нельзя не отметить, что другие реформаторы тоже писали к Катарине с уважением, например, Меланхтон обращался к «добродетельной и благочестивой супруге доктора» не иначе как к «особенной благополучной подруге». Он просил её писать ему без колебаний и обещал предоставить ей любую посильную помощь ${ }^{32}$.

Поддержка друзей семьи Катарине понадобилась действительно скоро. Изучая её сохранившуюся переписку, мы можем прийти к выводу, что жена Лютера никогда не упускала возможность извлечь выгоду из своих связей. На данный момент опубликовано 8 писем, написанных ей самой. Первое из них датируется 1539 годом, остальные были написаны уже после смерти мужа. Только первые два письма были адресованы близким людям, остальные же представляли собой просьбу о помощи и поддержке семьи покойного реформатора, с которой его вдова обращалась к влиятельным лицам.

30 TR 4, 631, 12-13, Nr. 5041.

31 Luther. 1542.

32 Melanchton. 1530. 
Первое письмо Катарины фон Бора адресовано казначею курфюрста, Гансу фон Таубенхайму, её крёстному, которого жена Лютера просит стать посредником в аренде земли Бус чуть южнее Виттенберга ${ }^{33}$. В письме Катарина признаётся, что не хочет отягощать этим делом своего мужа, потому что по её настоянию три года назад он уже пытался арендовать эту землю у канцлера Брюка, но безуспешно, а теперь у него много своих забот. В конце письма она подчёркивает, что хотела бы в дальнейшем передать землю своим сыновьям, сохранив низкую земельную ренту. Таким образом, с этим письмом мы получаем ещё одно доказательство того, что хозяйские дела в семье вела Катарина, планируя будущее своих детей и упорно идя к намеченной цели даже спустя несколько лет, в то время как Лютер предпочитал лишний раз не связываться с мирскими финансовыми операциями.

Наиболее ясно проявляется отношение Катарины к мужу в письме, адресованном её невестке, Кристине фон Бора. Оно было написано спустя два месяца после смерти Лютера. В нём она называет супруга «дорогим человеком» и «любимым господином». Катарина сообщает, что после горестного события не может ни есть, ни пить, ни спать. Она даже готова была бы отдать целое королевство, лишь бы не потерять любимого мужа. В этом траурном пассаже прослеживается влияние застольных речей Лютера: мы уже упоминали, что свою Кату Мартин не променял бы ни на империю, ни на королевство. Вдова сокрушается не только о своём несчастье, но и о потере всего мира, которому её супруг «так хорошо послужил». В конце она объясняет причину своего долгого молчания: от слёз у неё не осталось сил, чтобы читать или

33 Luther K. 1539. 


\section{Мойса А.А. Катарина фон Бора}

писать. Даже подпись свидетельствует о глубоком страдании: «Катарина, утихшая вдова доктора Мартина Лютера»34.

Целью следующих писем Катарины стало устройство жизни её сыновей и просьба о поддержке в тяжёлых условиях Шмалькальденской войны. Как мы уже отмечали, её корреспонденты обладали властью и высоким социальным статусом: это и герцог Пруссии Альбрехт БранденбургАнсбахский, и король Дании Кристиан III, и курфюрст Мориц Саксонский. При этом, Катарина остаётся верной своей риторике: её муж так много сделал для протестантского общества, но «так мало людей думают о том, чтобы за великие деяния моего господина помочь его бедным сиротам» 35 .

Не всегда усилия матери оказывались успешными: так прусский герцог Альбрехт отказался спонсировать обучение старшего сына Лютера в Италии или Франции, о котором просила Катарина. Герцог находил, что молодой человек недостаточно прилежен, но в память об отце Реформации он согласился финансировать дальнейшую учёбу в Кёнигсберге.

Датскому монарху вдова Лютера писала три раза и получила от него два ответных письма. В 1546 году через знакомых мужа она просила защиты для своей семьи, её просьба была удовлетворена: уже в Магдебурге Катарина и её дети начали получать финансовую поддержку от короля, который отправил вдове 50 талеров. В благодарность она написала ему свое первое письмо, отразившее её взгляд на несчастья 1546 года. Стоит отметить, что Катарина пишет не только о своих личных переживаниях (потеря мужа, бедственное положение семьи), но и об общем горе немецких земель: «Началась эта опасная война, за которой последовало разо- 
рение земель нашего дорогого Отечества» ${ }^{36}$. Ей отнюдь не чуждо чужое несчастье: так она также благодарит короля за поддержку теологов Виттенбергского университета и просит помочь одному из них, Георгу Майору, который тоже вынужден влачить нищенское состояние, не зная, как прокормить десять детей.

Однако два последующих письма Катарины, датируемые 1550 и 1552 годами, всё больше сосредоточены на персональных проблемах и показывают, что семья Лютера терпела бедствия и едва ли находила признание, как наследники великого реформатора, которым необходимо помочь за заслуги отца семейства ${ }^{37}$. Если Кристиан III хотя бы вновь выслал сумму, равную 50 розеноблей ${ }^{38}$, незадолго до смерти Катарины, то новый курфюрст Саксонии Мориц был глух к её просьбам.

В 1547 году в Саксонии произошла смена власти вследствие вынужденного отречения Иоганна-Фридриха Великодушного от своих земель. В изменившейся политической обстановке вдове Лютера, чьё имущество сильно пострадало от военных действий, было необходимо подтверждение её прав на наследство. Для этого ей пришлось обратиться в личную канцелярию курфюрста в Торгау, где от неё потребовали перечислить все права и пособия, закреплённые за ней прошлым правителем. Катарина подробно расписала в письме имущество, на которое претендовали она и её дети, попросила возобновить выплату пособий ей, как вдове, и вновь напомнила о стипендии сыновьям, которую обещал прошлый курфюрст. Тем не менее, эти просьбы не были осу-

37 Luther K. 1550.

38 Christian von Dänemark. 1552. 
ществлены, оставшись лишь частью многочисленных канцелярских дел ${ }^{39}$.

Итак, рассмотрев личную переписку Катарины фон Бора, мы приходим к выводу, что сильный характер этой женщины отличался от «покорного» идеала. С одной стороны, она воплощает образец материнства, ни одно её письмо не обходится без упоминаний детей, её сыновей, чьё будущее она старательно пытается устроить. С другой стороны, утратив супруга, Катарина была вынуждена переступить порог родного дома, царства, где, по Лютеру, женщина ещё могла бы господствовать, и отстаивать свои права, просить за свою семью у власть имущих, герцогов, курфюрстов и королей. Хотя она и действовала от имени мужа, постоянно напоминая о его вкладе в Реформацию, сложно не согласиться с тем, что её упорство и практичность стали ключевыми факторами, которые помогли семье выжить в послевоенной разрухе.

Подводя итоги, мы можем заключить, что Катарина фон Бора является яркой представительницей своей эпохи, раскрывшейся не только в силу природных задатков (хотя такие качества, как упорство и предприимчивость сыграли тут немаловажную роль), но и благодаря смене общей парадигмы, обусловленной распространением протестантского учения. Праведная жена стала восприниматься как божественное создание, которое нужно любить, беречь и ценить. Ей было отдано господство над домом, чем умело пользовалась и Катарина, осторожно расширяя рамки своего влияния. Как верная спутница, она уважала своего мужа и считала, что он занят великими делами ради всеобщего блага, поэтому она безропотно брала на себя бытовые хлопоты и даже роль кормильца семьи. Лютер, в свою очередь, желая подчеркнуть 
значимость института брака в протестантизме, не изолировал жену от внешнего мира, напротив, он открыто делился радостями супружества, противопоставляя их гнёту целибата.

Таким образом, можно сказать, что этот брак, на который многие приверженцы Лютера и он сам вначале смотрели с большой долей скептицизма, действительно стал наглядным образцом гармонии и любви, во многом соответствуя протестантскому идеалу супружества, описанному в трудах реформатора. 


\section{Список источников и китературы}

\section{Источники}

Christian von Dänemark. 1552 - Christian von Dänemark an Katharina Luther, 1552. Интернет-портал «Briefe der Reformationszeit»: http://briefe.glaubensstimme.de/1552/02/08/christian-vondaenemark-an-katharina-luther/(27.01.2020)

Luther. 1525 - Luther an Nikolaus von Amsdorf, 1525. Интернет-портал «Briefe der Reformationszeit»:http://briefe.glaubensstimme.de/1525/06/30/luther-annikolaus-von-amsdorf/(27.01.2020)

Luther. 1529 - Luther Martin an seine Ehefrau vom 4 Oktober 1529. Интернет-портал «Briefe der Reformationszeit»: http://briefe.glaubensstimme.de/1529/10/04/luther-martin-an-seineehefrau-vom-4-oktober-1529/(27.01.2020)

Luther. 1530a - Luther Martin an seine Ehefrau, 1530. Интернет-портал «Briefe der Reformationszeit»: http://briefe.glaubensstimme.de/1530/08/14/luther-martin-an-seineehefrau/(27.01.2020)

Luther. 1530b - Martin Luther an Kaethe 15 August 1530. Интернет-портал «Briefe der Reformationszeit»: http://briefe.glaubensstimme.de/1530/08/15/martin-luther-ankaethe-15-august-1530/(27.01.2020)

Luther. 1534 - Luther Martin an seine Ehefrau, 1534. Интернетпортал «Briefe der

Reformationszeit»: http://briefe.glaubensstimme.de/1534/07/29/luther-martin-an-seinefrau-aus-torgau-vom-29-juli-1534/(27.01.2020)

Luther. 1541 - Luther Martin aus Wittenberg vom 18 September 1541. Интернет-портал «Briefe der Reformationszeit»: http://briefe.glaubensstimme.de/1541/09/18/luther-martin-auswittenberg-vom-18-september-1541/(27.01.2020)

Luther. 1542 - Luthers Testament, 1542. Интернет-портал «Briefe der Reformationszeit»: http://www.glaubensstimme.de/doku.php?id=autoren:l:luther:t:luthers testament (27.01.2020)

Luther. 1546a - Luther Martin Brief an seine Frau 1546. Интернет-портал «Briefe der

Reformationszeit»: http://briefe.glaubensstimme.de/1546/02/10/luther-martin-brief-anseine-frau-1546/(27.01.2020) 
Luther. 1546b - Luther Martin an seine Frau aus Eisleben vom 7 Februar 1546. Интернет-портал «Briefe der Reformationszeit»: http://briefe.glaubensstimme.de/1546/02/07/luther-martin-an-seinefrau-aus-eisleben-vom-7-februar-1546/(27.01.2020)

Luther K. 1539 - Chatharina Luther an Hans von Traubenheym, Landrentmeister 28.4.1539. Интернет-портал «Briefe der Reformationszeit»: $\quad$ http://briefe.glaubensstimme.de/1539/04/28/catharinaluther-an-hans-von-taubenheym-landrentmeister-28-4$\underline{1539 /(27.01 .2020)}$

Luther K. 1546 - Katharina Luther an Christiana von Bora, 1546. Интернет-портал «Briefe der Reformationszeit»: http://briefe.glaubensstimme.de/1546/04/02/katharina-luther-anchristiana-von-bora/(27.01.2020)

Luther K. 1547 - Katharina von Bora an Christian von Dänemark, 1547. Интернет-портал «Briefe der Reformationszeit»: http://briefe.glaubensstimme.de/1547/02/09/katharina-von-bora-anchristian-von-daenemark/(27.01.2020)

Luther K. 1549 - Luther Katharina an Hz. Albrecht, 1549. / Thoma A. Katharina von Bora: Historischer Roman. Jazzybee Verlag, 2012.

Luther K. 1550 - Katharina von Bora an Christian von Dänemark, 1550. Интернет-портал «Briefe der Reformationszeit»: http://briefe.glaubensstimme.de/1550/10/06/katharina-von-bora-anchristian-von-daenemark-2/(27.01.2020)

Melanchton. 1530 - Der Ehrbahren tugendsamen frau Catharina Lutherin, Doctorin, meiner besondern günstigen Freudian, 1530. Интернет-портал «Briefe der Reformationszeit»: http://briefe.glaubensstimme.de/1530/05/04/melanchthon-philippder-ehrbaren-tugendsamen-frau-catharina-lutherin-doctorin-meinerbesondern-guenstigen-freundin/(27.01.2020)

TR 1 - D. Martin Luthers Werke: kritische Gesamtausgabe: Tischreden. 1 Bd. Weimar, 1912-1921.

TR 2 - D. Martin Luthers Werke: kritische Gesamtausgabe: Tischreden. 2 Bd. Weimar, 1912-1921.

TR 3 - D. Martin Luthers Werke: kritische Gesamtausgabe: Tischreden. $3 \mathrm{Bd}$. Weimar, 1912-1921.

TR 4 - D. Martin Luthers Werke: kritische Gesamtausgabe: Tischreden. 4 Bd. Weimar, 1912-1921. 
Мойса А.А. Катарина фон Бора

\section{ЛИТЕРАТУРА}

Гобри. 2000 - Гобри И. Лютер. М.: Молодая гвардия, 2000.

Kramer. 2016 - Kramer S. Katharina von Bora in den schriftlichen Zeugnissen ihrer Zeit. Leipzig: Evangelische Verlagsanstalt GmbH, 2016. 